\title{
Thermal characteristics analysis of an IGBT using a fiber Bragg grating
}

\author{
João Paulo Bazzo ${ }^{\mathrm{a}}$, Tiago Lukasievicz ${ }^{\mathrm{a}}$, Marcio Vogt ${ }^{\mathrm{a}}$, Valmir de Oliveira ${ }^{\mathrm{b}}$, \\ Hypolito José Kalinowski ${ }^{\text {}}$, Jean Carlos Cardozo da Silva ${ }^{\text {a }}$ \\ Federal University of Technology - Paraná (UTFPR) \\ ${ }^{a}$ Electrical Engineering Graduate Program (PPGEE) , 85503-390 Pato Branco, Brazil \\ ${ }^{\mathrm{b}}$ Graduate Program on Electrical Engineering and Applied Computer Science (CPGEI), 80230-901 \\ Curitiba, Brazil \\ Contact: jeanccs@utfpr.edu.br or jpbazzo@utfpr.edu.br
}

\begin{abstract}
This paper proposes a new method to develop a thermal model of an insulated gate bipolar transistor (IGBT) employing an optical fiber sensor mounted on the chip structure. Some features of the sensor such as electromagnetic immunity, small size and fast response time, allow the identification of temperature changes generated by the energy loss during device operation through direct measurement. In fact, this measurement method is considered impossible with conventional sensors. The online monitoring of the junction temperature enables identify the thermal characteristics of the IGBT. The results are used to develop an accurate model to simulate the heat generated during the device conduction and switching processes. The model showed a difference of only $0.3 \%$ between measured and simulated results, besides allowing evaluate separately the heat generated by each turn-ON/OFF process.
\end{abstract}

Keywords: IGBT thermal model, semiconductor junction temperature, thermal analysis, optical fiber Bragg grating sensor.

\section{INTRODUCTION}

Power semiconductor devices, especially IGBTs have been widely used in the application of electric motor drives, switching supplies, and other power conversion systems [1] [2]. To meet the power demand of such applications, advances technology in terms of materials and manufacturing techniques, have enabled the development of power semiconductor devices capable of operating at switching frequencies and current densities ever higher. Consequently, variations in voltage and current through the IGBT will also increase [2]. This has a direct impact on the dynamic performance of the devices, affecting the power losses and consequently raising the temperature of operation, because losses are dissipated as heat [3].

The design of power electronic circuits requires accurate information about the junction temperature of the switch to determine its performance, life-time, and reliability, given the temperature influence on the semiconductor characteristics [3] [4] [5]. Several dominant physical parameters associated with semiconductor devices are sensitive to temperature variations causing their dependent device characteristics to change dramatically [4] [5]. Among the most important of these parameters can be highlighted: the minority carrier lifetimes, the hole and electron mobilities, the free-carrier concentrations and intrinsic carrier concentration. Particularly the IGBT has two additional temperature dependent parameters, the MOS-gate threshold voltage and MOS-channel transcondutance [5], which leads to variations in temperature causing changes in the voltage and current waveforms of the IGBT, altering the power losses. Thus, the performance analysis of an IGBT must always be associated with its operating temperature [5] [6].

The online monitoring of IGBT temperature is very useful for enhancing the reliability, cost effectiveness and performance of the power electronic system [1] [6]. However, it is difficult to obtain the actual junction temperature since it cannot be measured directly by conventional sensors, because of the limited space and electromagnetic interference generated by the switching frequency (in the range of $\mathrm{kHz}$ ) [1] [4] [6]. An alternative has been the use of thermal models developed from indirect measurements. In this type of measurement the sensor is in contact with the heat 
sink, and the junction temperature is estimated by using a thermal calculation that considers all the layers that form the IGBT module. Although it has achieved significant results, this method is complex and presents a high level of uncertainty, because it requires a great knowledge about the materials' characteristics that make up the layers of the IGBT module [3] [7].

In this paper a new technique to directly monitor the junction temperature of the IGBT under transient condition is presented. The measurement relies on an optical fiber Bragg grating sensor positioned on top of the IGBT [8]. Due to the sensor's electromagnetic immunity and fast response time (order of microseconds), direct measurement can be done reliably [9] [10]. In addition to the online monitoring, the sensor can identify the thermal characteristics of IGBT structure, facilitating the development of accurate models to simulate the heat generated during switching and conduction processes [7] [11]. In comparison with other techniques based on indirect measurements [1] [7] [11], which show errors differences between measurements and simulations ranging from $10 \%$ and $20 \%$, this new technique showed a difference of only $0.3 \%$, approximately.

\section{EXPERIMENTAL SETUP AND METHODOLOGY}

The IGBT module SK45GB063, manufactured by SEMIKRON ${ }^{\circledR}$, is used for the analysis described in this paper. The IGBT operation can be defined, in brief, as a switch driven by voltage. To put the device in operation mode, it simply polarizes the positive collector terminal $(\mathrm{c}+)$ relative to the emitter terminal (e-). Thus, applying a positive voltage on gate terminal $(\mathrm{g})$, the device will switch to the on state (turn-ON) when the voltage at the gate exceeds the threshold voltage. The IGBT switches to off (turn-OFF) when the cut-off voltage of the gate terminal $(\mathrm{g})$. A test circuit with a resistive load, as shown in Figure 1(a), was implemented to drive the IGBT module (DUT - Device Under Test). In this circuit, a function generator that provides the signal for the gate can control the pulse width, and by changing the voltage $\mathrm{V}_{\mathrm{cc}}$ it is possible to change the load current. The shunt resistor $\mathrm{R}(0.01 \Omega)$ is used to measure the current through the DUT. The resistive load keeps a fixed value of current $I_{c}$ during the IGBT conduction state. The idea is to maintain the same power dissipation and measure the resulting change in temperature [8]. The junction temperature is monitored by a fiber Bragg grating sensor placed inside of the module, in direct contact with the IGBT wafer, as shown in Figure 1(b). In order to assemble the temperature sensor the top lid of the module case was removed and the sensor was fixed by a mineral oil that also improves the thermal contact between the sensor and the IGBT. An optical interrogator (FiberSensing ${ }^{\circledR}$ Industrial BraggSCOPE - FS2500) that transmits online information to a computer is used to interrogate the fiber Bragg grating sensor.

The junction temperature variation $\Delta \mathrm{Tj}$ (equation 1) depends on the power dissipation and thermal impedance $\mathrm{Z}_{\mathrm{th}}$ of the structure, which defines the heat flow through the device as a function of time [4] [7]. The function $Z_{t h}(t)$ (equation 2) is defined by the thermal resistances and capacitances, $\mathrm{R}_{\mathrm{th}}$ and $\mathrm{C}_{\mathrm{th}}$, respectively, and these are material characteristics [7].

$$
\begin{gathered}
\Delta T_{j}(t)=P(t) \cdot Z_{t h}(t) \\
Z_{t h}(t)=R_{t h}\left(1-\exp \left(\frac{-t}{R_{t h} \cdot C_{t h}}\right)\right)
\end{gathered}
$$

\section{RESULTS AND DISCUSSION}

To obtain the experimental results, a test was carried out driving the IGBT with the following parameters: bus voltage $\mathrm{V}_{\mathrm{cc}}=50 \mathrm{~V}$, colletor-emiter voltage in conduction state $\mathrm{V}_{\mathrm{ce}}=1,7 \mathrm{~V}$, collector current $\mathrm{I}_{\mathrm{c}}=1.3 \mathrm{~A}$, and pulse width of 20 seconds, as shown in Figure 2(a). As can be seen, the presence of $\mathrm{V}_{\mathrm{ce}}$ and $\mathrm{I}_{\mathrm{c}}$ causes a power dissipation equal to $1.98 \mathrm{~W}$ during the conduction state, while at the same time the junction temperature was monitored by the FBG placed in direct contact with the structure. The curve $\Delta \mathrm{T}_{\mathrm{j}}$ of Figure 2(a) shows the heat generated by conduction losses, where the maximum variation was $1.26^{\circ} \mathrm{C}$. It can also be observed that the peak power generated by the ON-OFF switching losses (turn-ON at $\mathrm{t}=4 \mathrm{~s}$ and turn-OFF at $\mathrm{t}=24 \mathrm{~s}$ ) is not detected by the sensor. This is because of the interrogator acquisition rate, which is limited to $2 \mathrm{kHz}$, and a $2 \mathrm{MHz}$ sampling rate is required for such a measurement [8]. Another fact is that the low energy dissipated during the switching process is not sufficient to sensitize the sensor (further demonstrated through model simulation). However, by using these results (Figure 2(a)) and equations $1-2$, it is possible to obtain the 
thermal impedance curve of the structure shown in Figure 2(b). The thermal characteristics of the structure can be obtained by doing a best-fit of the curve, where the maximum value in steady state is thermal resistance $\mathrm{R}_{\text {th }}$ given in ${ }^{\circ} \mathrm{C} / \mathrm{W}$, and the time constants of transient state determines by equation 3 the thermal capacitance $\mathrm{C}_{\mathrm{th}}$ in $\mathrm{J} /{ }^{\circ} \mathrm{C}$ [7]. The best fit found was the second-order exponential (equation 4), where values obtained were $\mathrm{R}_{\mathrm{th}}=0.65{ }^{\circ} \mathrm{C} / \mathrm{W}, \mathrm{C}_{\mathrm{th} 1}=1.13 \mathrm{~J} /{ }^{\circ} \mathrm{C}$ and $\mathrm{C}_{\mathrm{th} 2}=9.73 \mathrm{~J} /{ }^{\circ} \mathrm{C}$. The two thermal capacitance values are considered to obtain an accurate model of the IGBT thermal behavior, because the thermal impedance curve (Figure 2(b)) obtained in experimental testing showed two time constants.

$$
\begin{gathered}
C_{t h}=\tau / R_{t h} \\
Z_{t h}(t)=\left(\frac{R_{t h}}{2}\left(1-\exp \left(\frac{-t}{R_{t h} \cdot C_{t h 1}}\right)\right)\right)+\left(\frac{R_{t h}}{2}\left(1-\exp \left(\frac{-t}{R_{t h} \cdot C_{t h 2}}\right)\right)\right)
\end{gathered}
$$

The obtained parameters were used to design an RC model that allows simulation the heating of the junction in the IGBT, as shown in Figure 3. The second order dependence can be justified by making a comparison with the model proposed by Ciappa et al.[7], where the structure of the silicon is also represented by a second order model, because the thermal impedance was obtained by direct measurement between the structure and the sensor, considering only the silicon characteristics. So the other layers of the module, as welding, copper and encapsulation can be neglected, facilitating the development of the model.

The model validation was done comparing measured, Figure 2(a), and simulated results of the same experimental procedure. As it can be seen in Figure 4(a), there is a great similarity between the simulation and the measured response by the optical fiber sensor. This shows that the model can accurately reproduce the temperature variation that occurs at the junction of the IGBT due to the losses. Another dynamic test was performed by applying bus voltage $\mathrm{V}_{\mathrm{cc}}=100 \mathrm{~V}$, with a pulses sequence of $500 \mathrm{~ms}$. The comparison between simulation and measurement is shown in Figure 4(b), where the maximum difference is only of $\pm 0.02{ }^{\circ} \mathrm{C}$, which represents a discrepancy of approximately $0.3 \%$. This result shows a significant reduction of difference between measured and simulated results, when compared to other techniques, that use conventional sensors installed in the heat sink and present a minimum difference of 10\% [3] [7]. Another important point is that largest difference between simulation and measurement, concerns the fall in temperature (Figure 4(b)). This is because the model parameters were obtained through the thermal impedance curve by applying a fixed power (when the IGBT temperature is rising (Figure 2)), which explains the great similarity in peak temperature.

Although the monitoring system is not able to indentify the temperature variation caused by the power peaks of ON-OFF process due to the rate of acquisition of the optical interrogator and the small amount of energy dissipated in these processes, the thermal model can be used to simulate the heating generated by each switching process. This was verified by simulating the same power peak generated during the processes of turn-ON and turn-OFF in test of Figure 2(a). Figure 5 shows the detail of these transition intervals, where the turn-ON and turn-OFF processes are shown in Figure 5(a) and Figure 5(b), respectively. As can be seen, the presence of voltage $V_{c e}$ and current $I_{c}$ levels during switching processes causes a power peak, resulting in switching losses.

The same peak power obtained in the experimental testing (Figure 5) was replicated in the simulation model to estimate the heating for each switching process. The simulation results for turn-ON and turn-OFF process are shown in figures 6(a) and 6(b), respectively. As can be seen, the energy dissipated in the turn-ON process causes a temperature variation of approximately $0.017^{\circ} \mathrm{C}$. In the turn-OFF process, due to higher energy dissipation (topology characteristic of the IGBT used [4] [5]), the temperature variation is approximately $0.021{ }^{\circ} \mathrm{C}$. These results show that even with a high acquisition rate, analyzing the peak generated by each transition may present several difficulties due to small variations in junction temperature. However, through the model can evaluate separately the contribution of turn-ON and turn-OFF losses on the total heating device. This feature can be of great importance in the design of heat sinks and temperature controllers, because the energy dissipated in the switching processes accumulates and may cause the device junction temperature reaches above $150^{\circ} \mathrm{C}$ for frequencies in the order of $\mathrm{kHz}$ [12]. The operation in these temperature ranges may affect the stability and efficiency of the IGBT, and there is also the possibility of permanently damaging the device [3] [4]. 


\section{CONCLUSIONS}

The use of a fiber Bragg grating positioned over the IGBT structure provides a new method to directly monitor the temperature changes due to the device losses, a feature that was considered impossible in recent literature [1] [2]. Although the acquisition rate of the optical interrogator did not allow identifying the heat generated by each switching process, sensor measurements during pulses of long duration provided enough results that were the basis to identifying the thermal parameters of the IGBT structure. Such parameters were used for designing of a second order RC model, which allow the accurate simulation of the thermal behavior due to the losses in the device, with a discrepancy of about $0.3 \%$ compared the measurements. The RC model also allowed us to estimate the heat generated by each ON-OFF transition. The thermal model can be applied in design of power converters systems, where the analysis of the switching processes helps in choosing the best IGBT technology to be applied in the circuit. An accurate thermal model also facilitates the design of heat sinks and temperature control systems, which helps to ensure maximum efficiency in energy processing, preventing the temperature variation influences the switching losses.

\section{ACKNOWLEDGMENTS}

We acknowledge FINEP, CAPES, SETI, CNPq and Fundação Araucária (Brazilian Agencies) for the support to the laboratories. The used gratings were recorded at the Photo-refractive Devices Unit of UTFPR.

\section{REFERENCES}

[1] Shen, Y.; Xiong, Y.; Jiang, J. Yan Deng; He, X.; Zeng, Z. Switching Loss Analysis and Modeling of Power Semiconductor Devices Base on an Automatic Measurement System. IEEE International Symposium on Industrial Electronics 2006, 853-858.

[2] Ishiko, M.; Kondo, T. A Simple Approach for Dynamic Junction Temperature Estimation of IGBTs on PWM Operating Conditions. IEEE Power Electronics Specialists Conference 2007, 916-920.

[3] Xu, D.; Lu, H.; Huang, L.; Azuma, S.; Kimata, M. Uchida, R. Power loss and junction temperature analysis of power semiconductor devices. IEEE Transactions on Industry Applications 2002, 38, 1426-1431.

[4] Pan, Z., Xinjian, J., Lu, H. and Huang, L. Junction Temperature Analysis of IGBT Devices. IEEE Power Electronics and Motion Control Conference 2000, 3, 1068-1073.

[5] Santi, E.; Xiaosong Kang; Caiafa, A.; Hudgins, J.L.; Palmer, P.R.; Goodwine, D.Q.; Monti, A. Temperature effects on trench-gate punch-through IGBTs. IEEE Transactions on Industry Applications 2004, 40, 472-482.

[6] Kuhn, H., Mertens, A. On-line Junction Temperature Measurement of IGBTs based on Temperature Sensitive Electrical Parameters. 13th European Conference on Power Electronics and Applications 2009, 1-10.

[7] Ciappa, M., Fichtner, W., Kojima, T., Yamada, Y.; Nishibe, Y. Extraction of Accurate Thermal Compact Models for Fast Electro-Thermal Simulation of IGBT Modules in Hybrid Electric Vehicles. Microelectronics Reliability 2005, 45, 1694-1699.

[8] Bazzo, J. P.; Lukasievicz, T.; Vogt, M.; Martins, M. L. S.; Kalinowski, H. J.; Silva, J. C. C. Performance Evaluation of an IGBT Module by Thermal Analysis using Fiber Bragg Grating. Fourth European Workshop on Optical Fibre Sensors 2010, 7653, 1-4.

[9] Kersey, A.D.; Davis, M.A.; Patrick, H.J.; LeBlanc, M.; Koo, K.P.; Askins, C.G.; Putnam, M.A.; Friebele, E.J. Fiber grating sensors. Journal of Lightwave Technology 1997, 15, 1442-1463.

[10] James, S. W.; Tatam, R. P.; Fuller, S. R.; Crompton, C. Monitoring Transient Strains on a Gun Barrel Using Fiber Bragg-grating Sensor. Measurement Science and Technology 1999, 10, 63-67.

[11]Bruckner, T., Steffen, B. Estimation and Measurement of Junction Temperatures in a Three-Level Voltage Source Converter. IEEE Transactions on Power Eletronics 2007, 22, 3-12.

[12] Sheng, K., Williams, B. W., Finney, S. J. Maximum Operating Junction Temperature of PT and NPT IGBTs. IEEE Electronics Letters 1998, 34, 2276-2277. 


\section{LEGENDS}

Figure 1 - System setup. (a) Diagram of the DUT test circuit. (b) Position of the optical sensor inside the IGBT module SK45GB063 for online monitoring of the junction temperature.

Figure 2 - Test results. (a) Waveforms $V_{c e}, I_{c}$, power dissipation and junction temperature change for the experimental test with resistive load. (b) Thermal impedance of IGBT structure.

Figure 3 - IGBT RC thermic model.

Figure 4 - Comparison between measured and simulated results. (a) Temperature variation of the IGBT applied Vcc=50 V and pulse of 20 seconds. (b) Temperature variation of the IGBT applied Vcc $=100 \mathrm{~V}$ with pulse sequence of $500 \mathrm{~ms}$.

Figure 5 - Detail of Vce and Ic waveforms, and power dissipation during the switching processes of the test with $\mathrm{Vcc}=50 \mathrm{~V}$ and $\mathrm{RL}=33 \Omega$. (a) Time interval of the turn-ON process. (b) Time interval of the turn-OFF process.

Figure 6 - Simulation results of the heat generated by the switching processes of the test with Vcc=50 V and RL=33 $\Omega$. (a) turn-ON process. (b) turn-OFF process. 